University of Nebraska - Lincoln

DigitalCommons@University of Nebraska - Lincoln

USDA National Wildlife Research Center - Staff Publications
U.S. Department of Agriculture: Animal and Plant Health Inspection Service

$5-18-2007$

\title{
A Hierarchical Analysis of Habitat Selection by Raccoons in Northern Indiana
}

James C. Beasley

Department of Forestry and Natural Resources, Purdue University, beasley@srel.uga.edu

Travis L. DeVault

Department of Forestry and Natural Resources, Purdue University, Travis.L.DeVault@aphis.usda.gov

Monica I. Retamosa

Department of Forestry and Natural Resources, Purdue University, West Lafayette, IN

Olin E. Rhodes Jr.

Department of Forestry and Natural Resources, Purdue University, West Lafayette, IN, rhodes@srel.uga.edu

Follow this and additional works at: https://digitalcommons.unl.edu/icwdm_usdanwrc

Part of the Environmental Sciences Commons

Beasley, James C.; DeVault, Travis L.; Retamosa, Monica I.; and Rhodes, Olin E. Jr., "A Hierarchical Analysis of Habitat Selection by Raccoons in Northern Indiana" (2007). USDA National Wildlife Research Center - Staff Publications. 688.

https://digitalcommons.unl.edu/icwdm_usdanwrc/688

This Article is brought to you for free and open access by the U.S. Department of Agriculture: Animal and Plant Health Inspection Service at DigitalCommons@University of Nebraska - Lincoln. It has been accepted for inclusion in USDA National Wildlife Research Center - Staff Publications by an authorized administrator of DigitalCommons@University of Nebraska - Lincoln. 


\title{
A Hierarchical Analysis of Habitat Selection by Raccoons in Northern Indiana
}

\author{
JAMES C. BEASLEY, ${ }^{1}$ Department of Forestry and Natural Resources, 195 Marsteller Street, Purdue University, West Lafayette, IN 47907, USA \\ TRAVIS L. DEVAULT, ${ }^{2}$ Department of Forestry and Natural Resources, 195 Marsteller Street, Purdue University, West Lafayette, IN 47907, USA \\ MONICA I. RETAMOSA, ${ }^{3}$ Department of Forestry and Natural Resources, 195 Marsteller Street, Purdue University, West Lafayette, IN 47907, USA \\ OLIN E. RHODES, JR., Department of Forestry and Natural Resources, 195 Marsteller Street, Purdue University, West Lafayette, IN 47907, USA
}

\begin{abstract}
Although numerous studies have examined habitat use by raccoons (Procyon lotor), information regarding seasonal habitat selection related to resource availability in agricultural landscapes is lacking for this species. Additionally, few studies using radiotelemetry have investigated habitat selection at multiple spatial scales or core-use areas by raccoons. We examined seasonal habitat selection of 55 (31 M, $24 \mathrm{~F})$ adult raccoons at 3 hierarchical orders defined by the movement behavior of this species (second-order home range, second-order core-use area, and third-order home range) in northern Indiana, USA, from May 2003 to June 2005. Using compositional analysis, we assessed whether habitat selection differed from random and ranked habitat types in order of selection during the crop growing period (season 1) and corn maturation period (season 2), which represented substantial shifts in resource availability to raccoons. Habitat rankings differed across hierarchical orders, between seasons within hierarchical orders, and between sexes within seasons; however, seasonal and intersexual patterns of habitat selection were not consistent across hierarchical orders of spatial scale. When nonrandom utilization was detected, both sexes consistently selected forest cover over other available habitats. Seasonal differences in habitat selection were most evident at the core-area scale, where raccoon selection of agricultural lands was highest during the maturation season when corn was available as a direct food source. Habitat use did not differ from availability for either sex in either season at the third-order scale. The selection of forest cover across both seasons and all spatial orders suggested that raccoon distribution and abundance in fragmented landscapes is likely dependent on the availability and distribution of forest cover, or habitats associated with forest (i.e., water), within the landscape. The lack of consistency in habitat selection across hierarchical scales further exemplifies the need to examine multiple biological scales in habitat-selection studies. (JOURNAL OF WILDLIFE MANAGEMENT 71(4):1125-1133; 2007)
\end{abstract}

DOI: $10.2193 / 2006-228$

KEY WORDS agriculture, core area, corn, fragmentation, habitat use, hierarchy, Indiana, Procyon lotor, raccoon, scale.

Currently there is a growing awareness that our understanding of ecological processes can be influenced greatly by the spatial or biological context in which they are investigated (Bowyer and Kie 2006). Recognizing this potential bias, recent studies evaluating resource selection by wildlife have accentuated the need to examine multiple spatial scales in habitat-selection studies (Aebischer et al. 1993, Pedlar et al. 1997, Gehring and Swihart 2003, Bowyer and Kie 2006). Although the differential selection of habitats across various spatial scales certainly can occur in relatively homogeneous environments, the influence of resource distribution and animal movement behavior upon studies of habitat selection likely is greatest in the diverse matrix of landscape attributes that exemplify heavily fragmented landscapes. Although habitat fragmentation can occur within the context of numerous ecosystems, perhaps one of the best known examples of habitat fragmentation is in the midwestern United States, where forest cover persists as a mosaic of small forest patches within a matrix dominated by agricultural crops and anthropogenic features (Iverson 1988, Andersen et al. 1996, Spetich et al. 1997). Interestingly, the result of such

1 E-mail: beasley@purdue.edu

2 Present address: United States Department of Agriculture/Wildlife Services, National Wildlife Research Center, 5757 Sneller Road, Brewerton, NY 13029, USA

${ }^{3}$ Present address: Instituto Internacional en Conservación y Manejo de Vida Silvestre, Universidad Nacional, Apartado 1350-3000 Heredia, Costa Rica fragmentation also comes with a tremendous change in the abundance and temporal availability of food resources at many trophic levels within the landscape.

The raccoon (Procyon lotor), a generalist mesopredator common in the Midwest, represents a consummate biological model for investigation of the potential impacts of differential resource partitioning at varying spatial scales upon habitat selection of species inhabiting highly fragmented agricultural landscapes. Raccoon life-history characteristics and habitat requirements are well described, and raccoon populations thrive in agricultural regions, presumably because of their ability to adapt to the displacement of native food resources with corn and other crops (Rivest and Bergeron 1981, Kaufmann 1982, Gehrt 2003). Individuals of this species vary greatly in terms of habitat use and are capable of surviving in virtually any landscape containing a water source, suitable den sites, and adequate foraging opportunities (Kaufmann 1982, Gehrt 2003). The plasticity demonstrated by raccoons allows them to exploit a wide variety of ephemeral habitats and food sources. Thus, raccoons are abundant in landscapes containing a diversity of cover types (Oehler and Litvaitis 1996).

Despite their general adaptability, raccoons are closely tied to forested habitats (Pedlar et al. 1997, Dijak and Thompson 2000, Chamberlain et al. 2003). In agriculturally fragmented landscapes, forested habitats contain the primary sources of food, cover, and shelter when crop fields are barren, and the distribution and availability of forest patches likely influences raccoon movements and abundance. For 
example, female raccoons preferentially select tree cavities to rear young (Endres and Smith 1993, Gehrt 2003, Henner et al. 2004), making forested habitats critical to raccoon reproduction.

When available, corn is the preferred food item of raccoons (Giles 1939, Rivest and Bergeron 1981, Kaufmann 1982). Raccoons begin using corn as a direct source of food during the milk stage and continue to use corn through harvest (Ohio Department of Natural Resources, Division of Wildlife 2001, MacGowan et al. 2006, Humberg et al. 2007). During this period, corn fields supply a superabundant and dependable source of food (Rivest and Bergeron 1981). Despite the fact that raccoons may not decrease the size of core-use areas or home ranges when corn is available (Beasley et al. 2007), the presence of corn likely influences daily movements and habitat selection of raccoons. In particular, the presence of mature corn may be critical to female raccoons during the rearing period.

Although numerous investigators have examined animal responses to habitat fragmentation (e.g., Nupp and Swihart 2000, Tigas et al. 2002, Swihart et al. 2003), few have directly examined the effects of crop availability or developmental stage on seasonal habitat selection by vertebrates (e.g., Vercauteren and Hygnstrom 1997, Gehring and Swihart 2003, Gosselink et al. 2003). Moreover, although core areas presumably contain landscape elements biologically important to raccoons, few studies have investigated habitat selection within core areas of raccoons (Chamberlain et al. 2003). We examined intersexual and seasonal habitat selection by raccoons throughout the crop growing season at multiple hierarchical levels of habitat use in a highly fragmented agricultural landscape. We based our spatial analyses of habitat use upon the hierarchical orders suggested by Johnson (1980; e.g., first order, second order, third order), which reflect habitat use of organisms across spatial scales defined by the movement behavior of those organisms. Our objectives were to quantify habitat selection by raccoons relative to corn development at 2 hierarchical orders, representing 3 spatial scales defined by raccoon behavior: 1) second-order home range, 2) second-order core-use area, and 3) third-order home range, and to determine the extent to which habitat selection differed as a function of scale in highly fragmented landscapes.

\section{STUDY AREA}

Our $1,165-\mathrm{km}^{2}$ study area was located in the Upper Wabash River basin (UWB) in north-central Indiana, USA, encompassing portions of Grant, Huntington, Miami, and Wabash counties (Beasley 2005). The topography within the UWB was flat, with gently rolling areas along river drainages at an average elevation of $243 \mathrm{~m}$ above sea level. Approximately $96 \%$ of the land area within the UWB was privately owned, $71 \%$ of which was in agricultural use. The primary agricultural crops in the UWB were corn and soybeans, with small interspersed fields of hay and small grains. Only $13 \%$ of the basin was forested, compared to an average of 19\% statewide (Moore and Swihart 2005). All contiguous forest tracts within the study area were confined to major drainages where frequent flooding or locally steep topography made the land unsuitable for crop production. The remaining native forests (predominantly oak-hickorymaple [Quercus-Carya-Acer]) in the basin were highly fragmented. Across $3523-\mathrm{km}^{2}$ study areas within the UWB landscape analyzed by Moore and Swihart (2005), $75 \%$ of the forest patches were $<5$ ha, $50 \%$ were $<2$ ha, and only $1 \%$ of patches were $>100$ ha.

\section{METHODS}

\section{Raccoon Capture and Radiotelemetry}

We captured 105 raccoons (62 M, 43 F) in April-May and July-August of 2003 and 2004 in 21 forest patches located throughout the study area. We selected patches based on their size, degree of isolation, and juxtaposition with various habitat types, to encompass as many combinations of these variables as possible. We captured raccoons using box livetraps (Tomahawk Live Trap Co., Tomahawk, WI) baited with commercial cat food. To maximize capture probabilities, we placed traps strategically throughout selected forest patches (along fallen logs and streams, near latrines, at the base of den trees, etc.). We immobilized captured raccoons with an injection of ketamine $\mathrm{HCl}$ and xylazine $\mathrm{HCl}$ at rates of $10 \mathrm{mg} / \mathrm{kg}$ and $0.8 \mathrm{ml} / \mathrm{kg}$ of estimated body mass, respectively (Hodges et al. 2000). We ear-tagged, weighed to the nearest $0.1 \mathrm{~kg}$, and aged (toothwear technique; Grau et al. 1970) all captured raccoons. We fitted only raccoons $\geq 1$ year old with radiotransmitters, and we attempted to distribute radios equally among sexes within forest patches. We fitted 83 raccoons $(48 \mathrm{M}, 35 \mathrm{~F}$ ) with neck collars and associated $250-\mathrm{g}$ very high frequency mortality-sensitive radiotransmitters (estimated life span 2 yr; Telemetry Solutions Ltd., Concord, CA). We processed and released 22 additional raccoons without transmitters because they did not meet our age or desired sex-ratio requirements. All trapping and handling methods conformed to Purdue University Animal Care and Use Committee policies under protocol 01-079.

We tracked radiocollared raccoons using truck-mounted dual yagi (null-peak) antennas equipped with digital readout compasses. We partitioned raccoons into focal groups (4-5 raccoons) and tracked each group 1 night/week. We recorded 1 location/hour (max. of 9 locations/night) for each animal during the peak hours of activity $(1 \mathrm{hr}$ after sunset to $1 \mathrm{hr}$ before sunrise). In addition, throughout the growing season we obtained diurnal locations biweekly for all animals to incorporate resting locations within homerange boundaries. We did not attempt to collect intensive telemetry data outside of the crop developmental period for use in seasonal habitat-selection analyses due to logistical constraints.

We assessed radiotelemetry precision (i.e., $\bar{x}$ error arc of bearings) and accuracy (i.e., the distance from the true location of the transmitter to the triangulated location) by collecting 90 location estimates from 347 bearings on 6 radiocollars placed at 6 geo-referenced positions unknown 
to the observer. We distributed beacon radiocollars throughout the study area $<1 \mathrm{~m}$ off the ground in areas utilized by radiocollared raccoons. We estimated precision of bearings and triangulation error to be $8.75^{\circ} \pm 0.40$ and $81 \mathrm{~m} \pm 4.65$, respectively $(\bar{x} \pm \mathrm{SE})$. Although the precision of bearings recorded from beacon transmitters was not exceptionally high for null-peak telemetry systems, it is unlikely that our telemetry precision negatively impacted the accuracy of our location estimates substantially because we took radiolocations from geo-referenced positions close to transmitters $(>75 \%$ were within $0.5 \mathrm{~km})$. In addition, our triangulation error $(81 \mathrm{~m})$ was minimal relative to the size of the prominent features in the landscape (forest patches, crop fields, etc.); thus, we deemed the use of buffers around point locations for subsequent analyses of habitat selection unnecessary.

We triangulated raccoon locations using 2 or more bearings (usually 4) from telemetry stations along roads. We calculated the spatial coordinates of telemetry stations using a handheld Global Positioning System. To minimize telemetry error, we triangulated locations from stations as close to raccoons as possible in the shortest time interval possible. We recorded all locations within $1 \mathrm{~km}$ of the telemetry stations, and we recorded most $(>75 \%)$ within $0.5 \mathrm{~km}$ of telemetry stations. We recorded all bearings for each radiolocation within a 20 -minute interval to reduce error associated with raccoon movement. Sequential bearings taken on several individuals $(>10)$ over a 15 -minute period from a single telemetry station indicated that raccoon travel speeds were not great enough to result in substantial $\left(>2^{\circ}\right)$ error from time-delayed bearings. We imported telemetry bearings into Locate III (Nams 2005) to calculate 95\% maximum likelihood confidence ellipses and individual point locations. To account for telemetry error, we excluded all individual locations with error ellipses larger than the mean patch size within our study area (4.5 ha).

\section{Home-Range Analyses}

The composition of habitats within ecosystems is rarely constant, and changes in habitat characteristics may have dramatic effects on the resource selection of organisms inhabiting such landscapes (Schooley 1994, Arthur et al. 1996). In particular, the importance of temporal scale in resource selection studies is magnified in dynamic landscapes and thus defining discrete periods for study may not be practical in rapidly changing habitats (e.g., growing plants, ice cover; Arthur et al. 1996). Although crop fields are constantly changing as crops develop, we selected seasons based on temporal shifts in food and cover observed in crop fields surrounding radiocollared raccoons, thus minimizing any within season changes in resource availability. We partitioned telemetry data into 2 seasons based on crop developmental stage: growing season (20 May-21 Jul), encompassing the V5-R2 stages of corn growth when the presence of crops forms a nearly contiguous source of cover throughout the landscape; and maturation season (22 Jul-25 Oct), representing the milk-mature (R3-R6) stages of corn development when corn is a primary food source for raccoons. We delineated specific dates for each period based on crop developmental data combined with raccoon damage data collected in a concatenate 2-year study in the same landscape (Humberg et al. 2007). Lehman (1984) observed that substantial damage to field corn by raccoons did not occur until the milk (R3) stage of plant development. Within our study area, corn reached the milk stage on approximately 22 July in both 2003 and 2004, and we did not observe substantial damage to field corn by raccoons until that period in the growing season (Humberg et al. 2007).

We used the Home Range Extension (HRE) in ArcView 3.3 (Rodgers and Carr 1998) to calculate fixed-kernel (Worton 1989) home-range estimates. We used biased cross-validation to calculate the smoothing parameter based on $95 \%$ and $50 \%$ isopleths of the space utilization distribution (UD). We calculated seasonal home range (95\% UD) and core-area sizes (50\% UD) for all raccoons with $\geq 25$ locations in a given season (Beasley et al. 2007).

\section{Land Cover}

Study area.-We quantified local and landscape habitat attributes using land-use, rivers and streams, and road maps. We produced a land-use map for the study area by manually digitizing polygon feature classes using United States Geological Survey digital orthophotos of 1-m resolution and taken in 1998 using ArcGis 9.0. We delineated habitats into 7 land-use classes: forest (closed-canopy forests [includes deciduous and evergreen forest types]); shrubland (from scattered trees in an open matrix to open-canopy forests); corridors (habitat with trees $>3 \mathrm{~m}$ and $<30 \mathrm{~m}$ in width spanning some distance between 2 larger habitats); grassland (open areas not allocated to agriculture); agriculture (all type of crops, not including tree plantations); water (open, nonlinear water bodies, rivers and streams $>3 \mathrm{~m}$ wide); anthropogenic (cities, farm houses delineated by the mowing line, and animal holding facilities); and roads. Agriculture was the dominant land use within the study area $(66 \%)$, followed by forest (15\%), anthropogenic $(6 \%)$, grassland $(6 \%)$, water $(3 \%)$, shrubland $(2 \%)$, road $(1 \%)$, and corridor $(1 \%)$. Two reservoirs (in locations where we did not radiocollar any raccoons) accounted for $75 \%$ of the total land area encompassed by water in the UWB. The remaining free-water sources primarily were limited to streams and vernal pools located within forest patches and wooded corridors; however, many of these water sources were ephemeral. Ground-truth surveys indicated that the habitat maps used to digitize our study area lacked the resolution necessary to accurately identify many seasonal free-water sources; therefore, we excluded water from all analyses of habitat selection. Seasonal home-range ( $95 \%$ UD) and core-area (50\% UD) contour intervals were intersected with the habitat map using the HRE (Rodgers and Carr 1998).

Almost all methods of habitat analysis require an arbitrary measure of habitat availability from which to compare habitat use. However, studies that use a predefined study area as a measure of habitat availability may bias habitat 
selection estimates if animals are monitored only in a small portion of that study area and the composition of habitat types differs between the overall study area and the region where marked animals occur (Aebischer et al. 1993). The total area used by radiocollared raccoons represented approximately $20 \%$ of our overall study area. To determine whether the composition of habitats in the region containing radiocollared raccoons differed from the composition of habitats in the overall study area, we used the HRE to generate an overall $100 \%$ minimum convex polygon (MCP) encompassing all radiolocations obtained for all individuals and intersected the overall MCP with the habitat map. We exported habitat attributes for the $\mathrm{MCP}$ and the overall study area to DBASE IV files and we used them to obtain the proportions of each habitat type in each of the 2 defined regions. We used a chi-square test to determine whether the proportions of habitat types differed between the total area used by radiocollared raccoons (MCP) and those of the overall study area (SAS software, version 9.1; SAS Institute, Cary, NC).

Spatial scale.-Conventional levels of habitat selection can be hierarchically ordered, but there is not necessarily a scale-dependent difference between levels within the hierarchy (Allen and Hoekstra 1990). However, hierarchical levels of resource selection defined by a species' behavior can provide inference to the selection of habitats by that species at disparate spatial scales, although these scales are constrained within the hierarchy. We assessed seasonal habitat selection at 3 hierarchical orders based on raccoon behavior, which we adapted from those suggested by Johnson (1980). First-order selection (selection of a location within a species' range) was beyond the scope of our study. To evaluate second-order selection, we compared the composition of habitats within seasonal male and female raccoon home ranges (95\% UD) to the habitat composition of the overall study area (second-order study-area scale). As a second measure of second-order selection, we compared the composition of habitats within seasonal core-use areas (50\% UD) of male and female raccoons to the composition of habitats within the overall study area (second-order corearea scale). For third-order selection, we compared the proportion of seasonal telemetry locations within each habitat type with the proportion of habitat available within seasonal home ranges of individual male and female raccoons (third-order home-range scale).

We used compositional analysis with multivariate analysis of variance (MANOVA; Aebischer et al. 1993) to determine whether habitat preferences differed from random $(P<$ $0.05)$ between seasons at each hierarchical order of spatial resolution for each sex. Compositional analysis determines nonrandom utilization by comparing the matrices of logratio-transformed use and availability distributions with a log-likelihood ratio test (Aebischer et al. 1993). Aebischer et al. (1993) recommended sample sizes $\geq 10$ and preferably $\geq 30$ in habitat selection studies using compositional analysis. However, significant differences from nonrandom use can be detected if the number of individuals exceeds the number of habitat types (Aebischer et al. 1993). Thus, 7 raccoons was the minimum number of individuals necessary to detect habitat selection for each sex within each season. We used MANOVA to rank habitats in order of preference during each season for male and female raccoons at each hierarchical order examined.

Compositional analysis uses individual animals as sample units, thereby avoiding autocorrelation and pseudoreplication problems encountered when telemetry locations are used as sampling units (Aebischer et al. 1993, Otis and White 1999, Kernohan et al. 2001). However, the logarithmic transformations underpinning compositional analysis require that each animal use all available habitat types (Aebischer et al. 1993). Because of the low prevalence of several habitat types in the UWB (e.g., wooded corridor, shrubland, grassland), most animals did not use at least one habitat, particularly at the third order of selection. Aebischer et al. (1993) recommended substituting a small, nonzero value for all null values of habitat use; however, Bingham and Brennan (2004) identified inflated probabilities of Type I errors for substitution values approaching zero (e.g., 0.001-0.0001), suggesting that habitat-selection studies using substituted values close to zero may have produced spurious results. Bingham and Brennan (2004) suggested that a substitution value between 0.003 and 0.007 minimized the Type I error rate in compositional analysis; therefore, we replaced all missing habitats within sex by season categories with a value of 0.003 .

\section{RESULTS}

\section{Study Area}

We failed to detect differences in the proportional composition of habitat types between the 100\% MCP encompassing all radiolocations and the overall study area $\left(\chi^{2}=2.33, P=0.802\right)$. Therefore, we assumed the overall MCP to be representative of the $1,166-\mathrm{km}^{2}$ study area in terms of the proportions of habitats available to raccoons and used the overall study area for all second-order habitat availability comparisons.

\section{Spatial Scale}

We used 98 seasonal home ranges $(54 \mathrm{M}, 44 \mathrm{~F})$ from 55 raccoons $(31 \mathrm{M}, 24 \mathrm{~F})$ that had $\geq 25$ locations for analyses of habitat selection (see also Beasley et al. 2007). At the second-order home-range scale, habitat use of males differed from availability during the growing season $\left(F_{5,23}\right.$ $=3.71, P=0.013)$ but did not differ during the maturation season $\left(F_{5,18}=2.55, P=0.065\right.$; Table 1$)$. Female habitat use differed from availability during both the growing season $\left(F_{5,15}=5.79, P=0.004\right)$ and maturation seasons $\left(F_{5,16}=\right.$ $5.51, P=0.004$; Table 1$)$. Forest cover ranked highest across both seasons for each sex, and both male and female raccoons selected forest cover relative to all other habitats during both seasons (except for $\mathrm{M}$ during the maturation season). To a lesser extent, sexual differences in habitat rankings were conspicuous during the growing season, when males selected grassland habitats, and during the maturation season, when females selected agricultural habitats (Tables 
Table 1. Statistical results of compositional analysis to assess raccoon habitat use including seasonal $F$-values, degrees of freedom (numerator, denominator), and $P$-values for the hypotheses that male and female raccoon habitat use did not differ from availability, Upper Wabash River basin, Indiana, USA, May 2003-June 2005 (growing: 20 May-21 Jul; maturation: 22 Jul-25 Oct).

\begin{tabular}{cllrrr}
\hline Spatial scale & Season & Sex $^{\mathbf{a}}$ & $\boldsymbol{F}$ & df & \multicolumn{1}{c}{$\boldsymbol{P}$} \\
\hline Second-order & \multirow{2}{*}{ Growing } & $\mathrm{F}^{*}$ & 5.79 & 5,15 & 0.004 \\
home range & & $\mathrm{M}^{*}$ & 3.71 & 5,23 & 0.013 \\
& Maturation & $\mathrm{F}^{*}$ & 5.51 & 5,16 & 0.004 \\
& & $\mathrm{M}$ & 2.55 & 5,18 & 0.065 \\
Second-order & Growing & $\mathrm{F}^{*}$ & 2.95 & 5,15 & 0.047 \\
core area & & $\mathrm{M}^{*}$ & 8.67 & 5,23 & $<0.001$ \\
& \multirow{2}{*}{ Maturation } & $\mathrm{F}^{*}$ & 16.53 & 5,16 & $<0.001$ \\
& & $\mathrm{M}^{*}$ & 14.04 & 5,18 & $<0.001$ \\
Third-order & \multirow{2}{*}{ Growing } & $\mathrm{F}$ & 0.76 & 5,15 & 0.593 \\
home range & & $\mathrm{M}$ & 0.57 & 5,23 & 0.725 \\
& \multirow{2}{*}{ Maturation } & $\mathrm{F}$ & 0.22 & 5,16 & 0.944 \\
& & $\mathrm{M}$ & 1.52 & 5,18 & 0.229 \\
\hline
\end{tabular}

${ }^{\text {a }}$ Sample sizes were uniform across all spatial scales (growing season: 22 F, $30 \mathrm{M}$; maturation season: $22 \mathrm{~F}, 24 \mathrm{M}$ ).

${ }^{*}$ Habitat use differed from availability at $\alpha=0.05$.

2, 3). In addition, both sexes (particularly F) avoided anthropogenic habitats during both the growing and maturation seasons (Tables 2, 3).

At the second-order core-area scale, habitat selection differed from availability $(P<0.05)$ during the growing and maturation seasons for both sexes (Table 1). Forest cover was ranked highest for both sexes and was selected over all other available habitats in both seasons (Tables 4, 5). After forest cover, the rankings of agriculture and corridors were highest and anthropogenic habitats lowest during the maturation season for both sexes (Tables 4, 5). At the third-order home-range scale, habitat selection did not differ from availability for either sex during either season $(P$ $>0.05$; Table 1).

\section{DISCUSSION}

Raccoons in the UWB exhibited differential selection of habitats between seasons within hierarchical levels of spatial resolution and between sexes within seasons; however, seasonal and intersexual patterns of habitat selection were not consistent across hierarchical orders. Previous studies examining habitat use of raccoons have identified seasonal (Schneider et al. 1971, Gehring and Swihart 2003) and intersexual (Fritzell 1978, Sherfy and Chapman 1980, Endres and Smith 1993, Chamberlain et al. 2003) differences in habitat selection. However, only Chamberlain et al. (2003) used radiotelemetry to explicitly examine habitat selection at multiple spatial scales and found little variation in habitat selection across spatial scales. The examination of habitat selection across multiple hierarchical orders of spatial resolution is particularly relevant to studies conducted in fragmented landscapes because important habitat components often are limited in such landscapes. As such, the utilization of critical habitat features likely is optimized at coarse rather than fine spatial scales.

In the present study, third-order habitat-selection analyses failed to identify the selection of forested habitat by raccoons, even though selection for forest was clearly evident in analyses of higher orders in the hierarchy. Although analyses of habitat use at fine spatial resolutions likely reflect seasonal patterns in habitat selection with better resolution than do those conducted at coarse resolutions, the results of the present study suggest that a multi-order hierarchical design likely provides greater insight into the selection of habitats by organisms inhabiting highly fragmented landscapes than is obtained through finescale analyses alone.

At the highest orders of selection (second-order home range; 95\% UD, second-order core area; 50\% UD), habitat

Table 2. Simplified ranking matrices for radiocollared female raccoons comparing habitat compositions within the $95 \%$ contour of fixed-kernel seasonal home ranges with the habitat availability within a 1,166- $\mathrm{km}^{2}$ region of northern Indiana, USA, from May 2003 through June 2005 (second-order home range). ${ }^{\mathrm{a}}$

\begin{tabular}{|c|c|c|c|c|c|c|c|}
\hline \multirow[b]{2}{*}{ Habitat type } & \multicolumn{6}{|c|}{ Habitat type } & \multirow[b]{2}{*}{$\operatorname{Rank}^{\mathrm{b}}$} \\
\hline & Forest & Agriculture & Corridor & Grass & Shrub & Anthro & \\
\hline \multicolumn{8}{|l|}{ Growing } \\
\hline Forest & . & +++ & +++ & +++ & +++ & +++ & 5 \\
\hline Agriculture & --- & . & + & + & + & +++ & 4 \\
\hline Corridor & --- & - & . & + & + & +++ & 3 \\
\hline Grass & --- & - & - & . & + & +++ & 2 \\
\hline Shrub & --- & - & - & - & . & + & 1 \\
\hline Anthro & --- & --- & --- & --- & - & . & 0 \\
\hline \multicolumn{8}{|l|}{ Maturation } \\
\hline Forest & . & + & +++ & +++ & +++ & +++ & 5 \\
\hline Agriculture & - & . & + & + & +++ & +++ & 4 \\
\hline Corridor & --- & - & . & + & + & +++ & 3 \\
\hline Grass & --- & - & - & . & + & +++ & 2 \\
\hline Shrub & --- & --- & - & - & . & + & 1 \\
\hline Anthro & --- & --- & --- & --- & - & . & 0 \\
\hline
\end{tabular}

${ }^{a}$ Cells in the matrix consist of $\bar{x}$ differences in the $\log$ ratios of used and available habitats for all raccoons divided by the SE (i.e., $t$-values). The sign of the $t$-values is indicated with positive or negative signs, and triple signs represent significant deviation from random at $\alpha=0.05$ (growing season: $20 \mathrm{May}-21$ Jul; maturation season: 22 Jul-25 Oct). Anthro = anthropogenic, Shrub = shrubland, Grass = grassland.

${ }^{\mathrm{b}}$ Rank is equal to the sum of the positive values in each row. Higher ranks indicate a more preferred habitat. 
Table 3. Simplified ranking matrices for radiocollared male raccoons comparing habitat compositions within the $95 \%$ contour of fixed-kernel seasonal home ranges with the habitat availability within a 1,166- $\mathrm{km}^{2}$ region of northern Indiana, USA, from May 2003 through June 2005 (second-order home range). ${ }^{\mathrm{a}}$

\begin{tabular}{|c|c|c|c|c|c|c|c|}
\hline \multirow[b]{2}{*}{ Habitat type } & \multicolumn{6}{|c|}{ Habitat type } & \multirow[b]{2}{*}{ Rank } \\
\hline & Forest & Grass & Agriculture & Corridor & Anthro & Shrub & \\
\hline \multicolumn{8}{|l|}{ Growing } \\
\hline Forest & . & + & +++ & +++ & +++ & +++ & 5 \\
\hline Grass & - & . & + & + & +++ & +++ & 4 \\
\hline Agriculture & --- & - & . & + & + & + & 3 \\
\hline Corridor & --- & - & - & . & + & + & 2 \\
\hline Anthro & --- & --- & - & - & . & + & 1 \\
\hline Shrub & --- & --- & - & - & - & . & 0 \\
\hline \multicolumn{8}{|l|}{ Maturation } \\
\hline Forest & . & + & + & + & +++ & +++ & 5 \\
\hline Grass & - & . & + & + & + & +++ & 4 \\
\hline Agriculture & - & - & . & + & + & + & 3 \\
\hline Corridor & - & - & - & . & + & + & 2 \\
\hline Shrubland & --- & - & - & - & . & + & 1 \\
\hline Anthro & --- & --- & - & - & - & . & 0 \\
\hline
\end{tabular}

${ }^{a}$ Cells in the matrix consist of $\bar{x}$ differences in the log ratios of used and available habitats for all raccoons divided by the SE (i.e., $t$-values). The sign of the $t$-values is indicated with positive or negative signs, and triple signs represent significant deviation from random at $\alpha=0.05$ (growing season: $20 \mathrm{May}-21 \mathrm{Jul}$; maturation season: $22 \mathrm{Jul}-25 \mathrm{Oct})$. Anthro = Anthropogenic, Shrub = shrubland, Grass = grassland.

${ }^{\mathrm{b}}$ Rank is equal to the sum of the positive values in each row. Higher ranks indicate a more preferred habitat.

use in the UWB differed among seasons within each sex. Both sexes selected forest cover preferentially during the growing and maturation seasons. However, at the secondorder home-range scale, the selection of forest over other habitat types during the maturation season was more evident for females than for males, both in terms of the significance of the overall compositional analysis (F: $P=0.004$; M: $P=$ 0.065 ) and the degree of support for the ranking of forest cover for each sex in this season. Nonetheless, selection of forested habitat by both sexes supports findings of previous studies examining habitat use by raccoons (e.g., Kuehl and Clark 2002, Chamberlain et al. 2003). Within the UWB, free water was limited primarily to streams and vernal pools located in forest patches, and many of the forest patches persist in this agricultural landscape solely because they contain a water source and are not easily cultivated. Thus, the concentration of water within forest patches likely accentuated the importance of forested habitat to raccoons in our study area. The high ranking of wooded corridors within core areas of male and female raccoons during the growing and maturation seasons suggested that corridors also may play a critical role in facilitating raccoon movements in agriculturally fragmented landscapes, even when agricultural crops are present.

We observed intersexual differences in habitat selection within seasons only at the second-order home-range scale.

Table 4. Simplified ranking matrices for radiocollared female raccoons comparing habitat compositions within the $50 \%$ contour of fixed-kernel seasonal home ranges (core areas) with the habitat availability within a 1,166- $\mathrm{km}^{2}$ region of northern Indiana, USA, from May 2003 through June 2005 (second-order core area). ${ }^{\mathrm{a}}$

\begin{tabular}{|c|c|c|c|c|c|c|c|}
\hline \multirow[b]{2}{*}{ Habitat type } & \multicolumn{6}{|c|}{ Habitat type } & \multirow[b]{2}{*}{$\operatorname{Rank}^{\mathrm{b}}$} \\
\hline & Forest & Corridor & Shrub & Grass & Agriculture & Anthro & \\
\hline \multicolumn{8}{|l|}{ Growing } \\
\hline Forest & . & +++ & +++ & +++ & +++ & +++ & 5 \\
\hline Corridor & --- & . & + & + & + & +++ & 4 \\
\hline Shrub & --- & - & . & + & + & + & 3 \\
\hline Grass & --- & - & - & . & + & + & 2 \\
\hline Agriculture & --- & - & - & - & . & + & 1 \\
\hline Anthro & --- & --- & - & - & - & . & 0 \\
\hline \multicolumn{8}{|l|}{ Maturation } \\
\hline Forest & . & +++ & +++ & +++ & +++ & +++ & 5 \\
\hline Corridor & --- & . & + & + & + & +++ & 4 \\
\hline Agriculture & --- & - & . & + & + & +++ & 3 \\
\hline Shrub & --- & - & - & . & + & + & 2 \\
\hline Grass & --- & - & - & - & . & + & 1 \\
\hline Anthro & --- & --- & --- & - & - & . & 0 \\
\hline
\end{tabular}

${ }^{a}$ Cells in the matrix consist of $\bar{x}$ differences in the log ratios of used and available habitats for all raccoons divided by the SE (i.e., $t$-values). The sign of the $t$-values is indicated with positive or negative signs, and triple signs represent significant deviation from random at $\alpha=0.05$ (growing season: $20 \mathrm{May}-21 \mathrm{Jul}$; maturation season: 22 Jul-25 Oct). Anthro = Anthropogenic, Shrub = shrubland, Grass = grassland.

${ }^{\mathrm{b}}$ Rank is equal to the sum of the positive values in each row. Higher ranks indicate a more preferred habitat. 
Table 5. Simplified ranking matrices for radiocollared male raccoons comparing habitat compositions within the $50 \%$ contour of fixed-kernel seasonal home ranges (core areas) with the habitat availability within a 1,166- $\mathrm{km}^{2}$ region of northern Indiana, USA, from May 2003 through June 2005 (second-order core area). ${ }^{a}$

\begin{tabular}{|c|c|c|c|c|c|c|c|}
\hline \multirow[b]{2}{*}{ Habitat type } & \multicolumn{6}{|c|}{ Habitat type } & \multirow[b]{2}{*}{ Rank $^{\mathrm{b}}$} \\
\hline & Forest & Corridor & Shrub & Grass & Agriculture & Anthro & \\
\hline \multicolumn{8}{|l|}{ Growing } \\
\hline Forest & . & +++ & +++ & +++ & +++ & +++ & 5 \\
\hline Corridor & --- & . & + & + & + & +++ & 4 \\
\hline Shrub & --- & - & . & + & + & + & 3 \\
\hline Grass & --- & - & - & . & + & + & 2 \\
\hline Agriculture & --- & - & - & - & . & + & 1 \\
\hline Anthro & --- & --- & - & - & + & . & 0 \\
\hline \multicolumn{8}{|l|}{ Maturation } \\
\hline Forest & . & +++ & +++ & +++ & +++ & +++ & 5 \\
\hline Corridor & --- & . & + & + & + & +++ & 4 \\
\hline Agriculture & --- & - & . & + & + & +++ & 3 \\
\hline Shrub & --- & - & - & . & + & + & 2 \\
\hline Grass & --- & - & - & - & . & + & 1 \\
\hline Anthro & --- & --- & --- & - & - & . & 0 \\
\hline
\end{tabular}

${ }^{a}$ Cells in the matrix consist of $\bar{x}$ differences in the $\log$ ratios of used and available habitats for all raccoons divided by the SE (i.e., $t$-values). The sign of the $t$-values is indicated with positive or negative signs, and triple signs represent significant deviation from random at $\alpha=0.05$ (growing season: $20 \mathrm{May}-21$ Jul; maturation season: 22 Jul-25 Oct). Anthro = Anthropogenic, Shrub = shrubland, Grass = grassland.

${ }^{\mathrm{b}}$ Rank is equal to the sum of the positive values in each row. Higher ranks indicate a more preferred habitat.

During the maturation season, female raccoons utilized agriculture to a greater extent than did males, and during the growing season males utilized grasslands to a greater extent than did females. Differential habitat selection between sexes of raccoons among seasons has been attributed to the maternal responsibilities of females (Fritzell 1978, Endres and Smith 1993) and the decreased movement of females during pregnancy (Schneider et al. 1971, Endres and Smith 1993). Thus, intersexual differences in the selection of agriculture during the maturation season likely reflected the additional resource needs of females due to maternal responsibilities. During the summer, grassland habitats provide access to a number of food resources, such as insects and avian nests. The increased utilization of grasslands by males during the growing season likely reflected the additional foraging opportunities grasslands provided prior to ear development in corn. Conversely, female raccoons typically select den trees to rear young (Endres and Smith 1999, Gehrt 2003), and they restrict movement around natal dens during that time (Schneider et al. 1971, Endres and Smith 1993, Kamler and Gipson 2003). Thus, the lack of selection for grasslands by females during the growing season may have reflected differences in reproductive constraints between sexes, as female movements were likely concentrated in forested areas proximal to den sites during the early stages of crop development.

Raccoons often shift habitat-use patterns and concentrate foraging within relatively small areas in response to changes in the temporal availability of resources (Kaufmann 1982, Henner et al. 2004). The selection of agricultural lands within core areas by both sexes during the maturation season suggested that habitat use by raccoons was directly influenced by crop availability. The shift in the selection of agriculture during the maturation season supports the findings of Henner et al. (2004), who observed a shift in raccoon habitat use and den-site selection in response to corn maturation. Furthermore, the nonrandom use of agriculture during the maturation season observed in our study is strongly reinforced by the observations of substantive raccoon damage to field corn at the onset of the milk stage in our study area (Humberg et al. 2007).

Core areas typically contain habitats of critical biological importance to raccoons such as den sites and quality foraging areas (Ewer 1968); thus, the nonrandom utilization of landscape elements at the core-area scale presumably was due to the limited presence of those habitats containing resources important to raccoons within the landscape. Although second-order home-range and second-order core-area analyses produced similar findings in our study, the examination of core areas elucidated the importance of forested habitats to a greater degree than did analyses performed at the second-order home-range scale, and identified the selection of agriculture during the maturation season, which was not detected at the second-order homerange scale. Thus, our examination of core-area habitat selection helped to identify vital landscape elements that might have been overlooked if habitat selection was examined only at the second-order home-range scale.

At the finest spatial resolution we measured (third-order home range), habitat use did not differ from habitat availability during any season. Resource selection is more likely to vary across hierarchical scales of spatial resolution in fragmented landscapes than in more homogeneous landscapes because of the patchy distribution of resources that results from forest fragmentation, forcing individuals to optimize resource use at coarse, rather than fine spatial scales. The differential selection of habitats across hierarchical orders of spatial resolution was particularly evident in our study, as fine-scale analyses (i.e., measures of thirdorder selection) failed to identify the importance of forest 
and agriculture that clearly was elucidated at higher-order scales.

\section{MANAGEMENT IMPLICATIONS}

Although numerous studies have demonstrated the plasticity of raccoons in terms of habitat requirements, in highly fragmented landscapes habitat plasticity may be diminished by the patchy distribution of critical resources (i.e., food, water). Our results suggest that in agriculturally fragmented landscapes, management strategies (e.g., habitat manipulations, direct removal, distribution of oral bait vaccines, etc.) could be highly effective at fine spatial scales because of the maintenance of small home ranges by raccoons across seasons, coupled with their high fidelity to forested habitats (Beasley 2005). We recommend that management efforts for raccoons be concentrated within forested areas, particularly during the non-growing season when food resources are limited to forested areas. In the present study, the selection of forested habitat across seasons and the selection of agricultural lands during the maturation season by females suggest that these resources may be most important to the reproductive success of raccoons in agricultural landscapes. However, the lack of consistency between second- and third-order scales reinforces the importance of hierarchical orders of scale in studies evaluating habitat selection.

\section{ACKNOWLEDGMENTS}

This study would not have been possible without the cooperation of numerous landowners in the UWB who permitted us access to their land. We thank L. Humberg, D. Glista, B. Graser, R. Jacques, G. Dharmarajan, M. Robles, W. Oles, S. Hansen, B. Beehler, T. Van Kleek, J. Stevens, K. Bailey, A. Hawkins, J. Ringell, E. Kellaher, K. Paullus, M. Lavelle, and A. Sweeten for their assistance in trapping and collecting radiotelemetry data. We also thank R. Swihart, S. Gehrt, H. Weeks, and 2 anonymous reviewers for their numerous substantive comments that improved the manuscript. This manuscript is based upon work supported by the Cooperative State Research, Education, and Extension Service, United States Department of Agriculture, under Agreement 2000-04649. The Indiana Department of Natural Resources, the National Wild Turkey Federation, the Indiana Chapter of the National Wild Turkey Federation, the John S. Wright Fund, and Purdue University also provided funding.

\section{LITERATURE CITED}

Aebischer, N. J., P. A. Robertson, and R. E. Kenward. 1993. Compositional analysis of habitat use from animal radio-tracking data. Ecology 74: 1313-1325.

Allen, T. F. H., and T. W. Hoekstra. 1990. The confusion between scaledefined levels and conventional levels of organization in ecology. Journal of Vegetation Science 1:5-12.

Andersen, O., T. R. Crow, S. M. Lietz, and F. Stearns. 1996. Transformation of a landscape in the upper mid-west, USA: the history of the lower St. Croix River valley, 1830 to present. Landscape and Urban Planning 35:247-267.

Arthur, S. M., B. F. J. Manly, L. L. McDonald, and G. W. Garner. 1996.
Assessing habitat selection when availability changes. Ecology 77:215227.

Beasley, J. C. 2005. Home range attributes and multi-scale habitat selection of raccoons (Procyon lotor) in northern Indiana. Thesis, Purdue University, West Lafayette, Indiana, USA

Beasley, J. C., T. L. DeVault, and O. E. Rhodes, Jr. 2007. Home range attributes of raccoons in a fragmented agricultural region of northern Indiana. Journal of Wildlife Management: 71:in press.

Bingham, R. L., and L. A. Brennan. 2004. Comparison of Type I error rates for statistical analyses of resource selection. Journal of Wildlife Management 68:206-212.

Bowyer, R. T., and J. G. Kie. 2006. Effects of scale on interpreting lifehistory characteristics of ungulates and carnivores. Diversity and Distributions 12:244-257.

Chamberlain, M. J., L. M. Conner, B. D. Leopold, and K. M. Hodges. 2003. Space use and multi-scale habitat selection of adult raccoons in Central Mississippi. Journal of Wildlife Management 67:334-340.

Dijak, W. D., and F. R. Thompson, III. 2000. Landscape and edge effects on the distribution of mammalian predators in Missouri. Journal of Wildlife Management 64:209-216.

Endres, K. M., and W. P. Smith. 1993. Influence of age, sex, season, and availability on den selection by raccoons within the central basin of Tennessee. American Midland Naturalist 129:116-131.

Ewer, R. F. 1968. Ethology of mammals. Logos Press, London, United Kingdom.

Fritzell, E. K. 1978. Habitat use by prairie raccoons during the waterfowl breeding season. Journal of Wildlife Management 42:118-127.

Gehring, T. M., and R. K. Swihart. 2003. Body size, niche breadth, and ecologically scaled responses to habitat fragmentation: mammalian predators in an agricultural landscape. Biological Conservation 109: 283-295.

Gehrt, S. D. 2003. Raccoon. Pages 611-634 in G. A. Feldhamer, B. C. Thompson, and J. A. Chapman, editors. Wild mammals of North America: biology, management, and conservation. Johns Hopkins University Press, Baltimore, Maryland, USA.

Giles, L. W. 1939. Fall food habits of the raccoon in central Iowa. Journal of Mammalogy 20:68-70.

Gosselink, T. E., T. R. Van Deelen, R. E. Warner, and M. G. Joselyn. 2003. Temporal habitat partitioning and spatial use of coyotes and red foxes in east-central Illinois. Journal of Wildlife Management 67:90-103.

Grau, G. A., G. C. Sanderson, and J. P. Rogers. 1970. Age determination of raccoons. Journal of Wildlife Management 34:364-372.

Henner, C. M., M. J. Chamberlain, B. D. Leopold, and L. W. Burger, Jr. 2004. A multi-resolution assessment of raccoon den selection. Journal of Wildlife Management 68:179-187.

Hodges, K. M., M. J. Chamberlain, and B. D. Leopold. 2000. Effects of summer hunting on ranging behavior of adult raccoons in Central Mississippi. Journal of Wildlife Management 64:194-198.

Humberg, L. A., T. L. DeVault, B. J. MacGowan, J. C. Beasley, and O. E. Rhodes, Jr. 2007. Crop depredation by wildlife in northcentral Indiana. Pages 199-205 in A. Stewart, editor. Proceedings of the Ninth National Wild Turkey Symposium, Grand Rapids, Michigan, USA.

Iverson, L. R. 1988. Land-use changes in Illinois, USA: the influence of landscape attributes in current and historic land use. Landscape Ecology 2:45-61.

Johnson, D. H. 1980. The comparison of usage and availability measurements for evaluating resource preference. Ecology 61:65-71.

Kamler, J. F., and P. S. Gipson. 2003. Space and habitat use by male and female raccoons, Procyon lotor, in Kansas. Canadian Field-Naturalist 117: 218-223.

Kaufmann, J. H. 1982. Raccoon and allies. Pages 567-585 in J. A. Chapman and G. A. Feldhamer, editors. Wild mammals of North America: biology, management, and economics. Johns Hopkins University Press, Baltimore, Maryland, USA.

Kernohan, B. J., R. A. Gitzen, and J. J. Millspaugh. 2001. Analysis of animal space use and movements. Pages 125-166 in J. J. Millspaugh and J. M. Marzluff, editors. Radio-tracking and animal populations. Academic Press, San Diego, California, USA.

Kuehl, A. K., and W. R. Clark. 2002. Predator activity related to landscape features in northern Iowa. Journal of Wildlife Management 66:12241234.

Lehman, L. E. 1984. Raccoon density, home range, and habitat use on 
south-central Indiana farmland. Pittman-Robertson Bulletin 11, Indiana Department of Natural Resources, Indianapolis, USA.

MacGowan, B. J., L. A. Humberg, J. C. Beasley, and O. E. Rhodes, Jr. 2006. Identification of wildlife crop depredation, FNR-267. Purdue University, Department of Forestry and Natural Resources, West Lafayette, Indiana, USA.

Moore, J. E., and R. K. Swihart. 2005. Modeling patch occupancy by forest rodents: incorporating detectability and spatial autocorrelation with hierarchically structured data. Journal of Wildlife Management 69:933949.

Nams, V. O. 2005. Locate III user's guide. Pacer Computer Software, Tatamagouche, Nova Scotia, Canada.

Nupp, T. E., and R. K. Swihart. 2000. Landscape-level correlates of smallmammal assemblages in forest fragments of farmland. Journal of Mammalogy 81:512-526.

Oehler, J. D., and J. A. Litvaitis. 1996. The role of spatial scale in understanding responses of medium-sized carnivores to forest fragmentation. Canadian Journal of Zoology 74:2070-2079.

Ohio Department of Natural Resources, Division of Wildlife. 2001. Wildlife crop damage manual. < http://www.dnr.state.oh.us/wildlife/ Resources/cropdamage $>$. Accessed 11 Nov 2005.

Otis, D. L., and G. C. White. 1999. Autocorrelation of location estimates and the analysis of radiotracking data. Journal of Wildlife Management 63:1039-1044.

Pedlar, J. H., L. Fahrig, and H. G. Merriam. 1997. Raccoon habitat use at 2 spatial scales. Journal of Wildlife Management 61:102-112.

Rivest, P., and J. M. Bergeron. 1981. Density, food habits, and economic importance of raccoons (Procyon lotor) in Quebec agrosystems. Canadian Journal of Zoology 59:1755-1762.
Rodgers, A. R., and A. P. Carr. 1998. HRE: the home range extension to Arc View. User's manual. Centre for Northern Forest Ecosystem Research, Ontario Ministry of Natural Resources, Thunder Bay, Canada.

Schneider, D. G., L. D. Mech, and J. R. Tester. 1971. Movements of female raccoons and their young as determined by radio-tracking. Animal Behavior Monographs 4:1-43.

Schooley, R. L. 1994. Annual variation in habitat selection: patterns concealed by pooled data. Journal of Wildlife Management 58:367-374.

Sherfy, F. C., and J. A. Chapman. 1980. Seasonal home range and habitat utilization of raccoons in Maryland. Carnivore 3:8-18.

Spetich, M. A., G. R. Parker, and E. J. Gustafson. 1997. Spatial and temporal relationships of old-growth and secondary forests in Indiana, USA. Natural Areas Journal 17:118-130.

Swihart, R. K., T. M. Gehring, M. B. Kolozsvary, and T. E. Nupp. 2003. Responses of 'resistant' vertebrates to habitat loss and fragmentation: the importance of niche breadth and range boundaries. Diversity and Distributions 9:1-18.

Tigas, L. A., D. H. VanVuren, and R. M. Sauvajot. 2002. Behavioral responses of bobcats and coyotes to habitat fragmentation and corridors in an urban environment. Biological Conservation 108:299-306.

Vercauteren, K. C., and S. E. Hygnstrom. 1997. Effects of agricultural activities and hunting on home ranges of female white-tailed deer. Journal of Wildlife Management 62:280-285.

Worton, B. J. 1989. Kernel methods for estimating the utilization distribution in home-range studies. Ecology 70:164-168.

Associate Editor: Bowman. 